\title{
HYPOTHESIS OF RFMRA \\ DEVELOPMENT - THE RECEPTOR-FOCUSED MAGNETIC AND RESONANT ANESTHESIA
}

\author{
Maxim Golyanishchev \\ Department of an anesthesiology and intensive care \\ Kharkiv Medical Academy of Post-graduate Education \\ 58 Amosov str., Kharkiv, Ukraine, 61176 \\ golyanischev@yandex.ru
}

\begin{abstract}
This article is described the hypothesis of the solution how to create the "ideal anesthesia". Theoretical justification of the innovative technique of the Receptor-focused Magnetic Resonance anesthesia is offered. It should be use the "ideal anesthetic" as which the electromagnetic model of a medicinal preparation for anesthesia acts. Stages of carrying out the offered type of anesthesia have offered. For the practical application of the proposed idea it would be implemented a number of innovations. First, it includes technologies of a magnetic and resonant tomography of high resolution (less than 100 microns). At the second, it would be technologies of creation electromagnetic models of the existing medical preparations. Than it would be on-line technologies of formation the 3D base of addresses of receptors for anesthesia of organism of a particular person. In addition, technologies of a triggering the cascade of biochemical reactions is proposed, by the modeling of pharmacodynamics electromagnetic models of a medicinal preparation.

Such type of anesthesia will allow to avoid side effects of medical preparations at stages of an absorption, distribution, removal that are caused by the mass of drug and, in addition, respectively, to reach therapeutic effect only by means of electromagnetic model of a medicinal preparation for anesthesia.
\end{abstract}

Keywords: anesthetic, electromagnetic model, magnetic resonance tomography, receptor, anesthesia, biochemical reactions.

\section{Introduction}

Development of "ideal anesthetic" remains an actual task of modern sciences. Because of all existing drugs have disadvantages of their pharmacokinetic and/or pharmacodynamic properties and side effects. One of the reasons of such disadvantages, as we consider, is existence of mass and chemico-physical features of molecules of anesthetics [1-4]. This work is the attempt to overcome this disadvantage.

Effects of drugs are realized after physical and chemical interaction of drug molecules and target receptors to them (Fig. 1) [1-3, 5-7]. In the same way, after accession of drug for anesthesia molecules to specific receptors there are corresponding medical effects and condition of anesthesia has been developing.

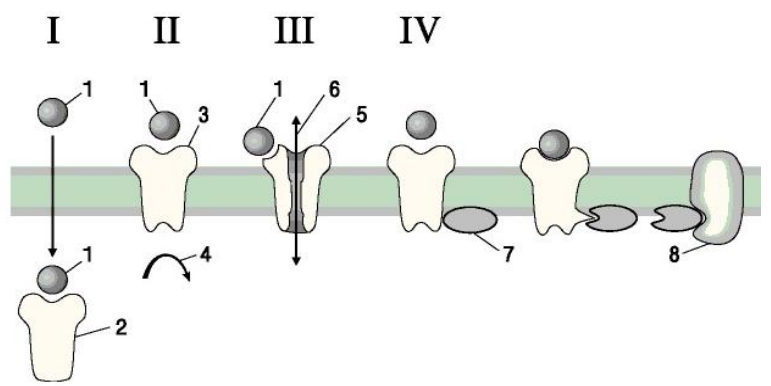

Fig. 1. Options of interactions of mediators and receptors

Simply it looks as follows: it has been interaction of drugs and a specific receptor of cells, than it's change of three dimension (3D) structure and chemico-physical properties of "receptors for narcosis" (RN). That causes the cascade of biochemical reactions with integrated effect of change of frequency and forces the depolarization streams of ions in the corresponding parts of the nervous system (Fig. 2). 


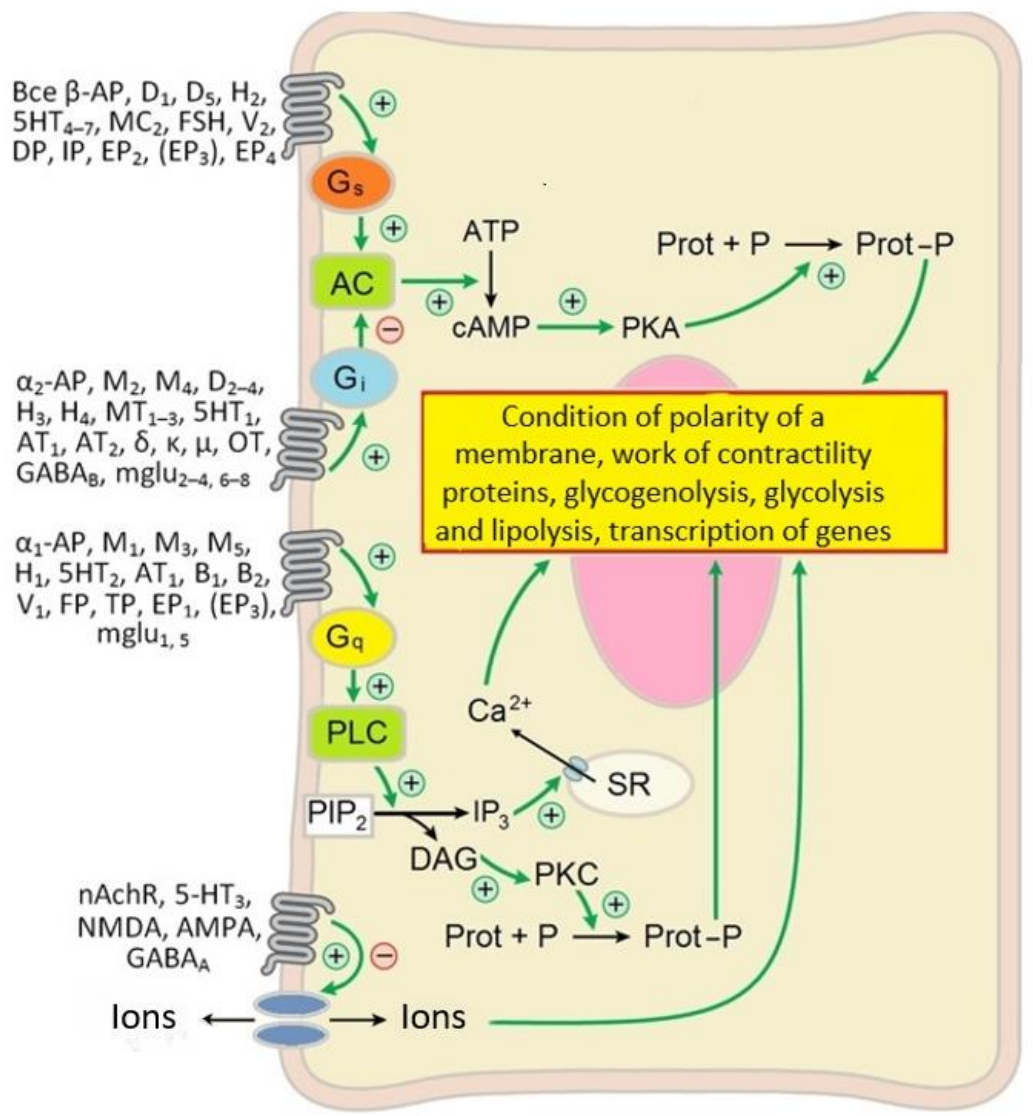

Fig. 2. Four mechanisms of the response of a cage to interaction of a receptor and mediator

Ideas of mechanisms of the regional anesthesia were reached essential development and explained the condition of regional anesthesia as a result of oppression of carrying out nervous impulse on nervous fibers that had caused by depression of intensity of ionic streams in sensitive neurons.

The theory of the general anesthesia did not receive uniform interpretation. The most general view, as we consider, that the general anesthesia is a result of decrease of the activity of integrative function of the central nervous system (CNS). This stage occurs because of change of activity (oppression or excitement) separate or the sum of the corresponding structural units of a nervous system. There is such change of the CNS function after change of 3D structure/chemico-physical properties of the RN and the subsequent change of transmembrane ionic streams in neurocytes of the corresponding units of a CNS [8-16].

Thus, anesthesia arises after change of chemico-physical properties and spatial orientation of a certain array of RN (Fig. 3).

Proceeding from above information, task is set: to develop an anesthesia method, which would allow to reach effects of anesthesia (the local or general) in the way, which would change transmembrane ionic streams by means of stimulation of the certain array of RN without the molecular, mass caused chemico-physical interaction.

\section{Aim of research}

To develop theoretical bases of a type of anesthesia, which would allow to reach effects of anesthesia (regional or the general) in the way, which would change activity of various structural units of a nervous system by the stimulation of the massive of "narcotic receptors" without the mass caused physical and chemical interaction. 


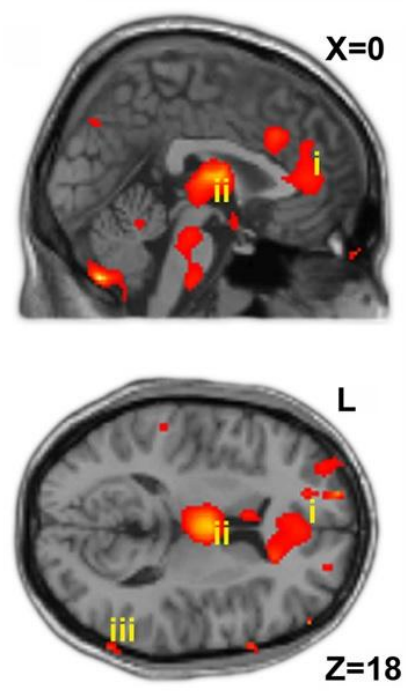

Fig. 3. Neural correlates associated with the ROC during constant dose of dexmedetomidine anesthesia. Sagittal (top) and axial (bottom) sections showing cingulate (i), thalamus (ii), inferior parietal cortex (iii), and brainstem activations [12]

\section{Materials and Methods}

As the solution, it is offered the following hypothesis: achievement of anesthesia effects is possible by of the Receptor-focused Magnetic Resonance anesthesia. This hypothesis is personal idea, which in short consists in the following.

1. Introduction: "receptor-drug" interaction occurs by means of and after interaction of electromagnetic fields (EMF) of a receptor and a preparation:

- each medicinal substance (MS) consists of atoms, which have "cloud" from unique on a 3D configuration of EMF;

- such "fields/clouds" create anesthetic molecule EMF - unique on a configuration for each MS (and for anesthetic too);

- same "fields/clouds" are created by EMFs of molecules of component RN;

- spatial orientation of EMF of molecules of anesthetics and receptors to them matches by the principle of congruence/complementarity (the lock-and-key principle, the hands-and-gloves principle, like locking in the mirror and seeing the reverse of things, etc.);

- the congruence/complementarity of EMFs provides specificity of interactions between substance and receptor;

- EMF of receptor "checks" MS without formation of the material communications (electronic, hydrogen, etc.) for compliance (congruence/complementarity, specificity) and only in case of matches - the lock-and-key - makes a connection with formation of chemical bonds, conformation changes of a receptor and the subsequent stage of biochemical responses [4, 17- 19].

Main part of a hypothesis: it is possible to run a cascade of biochemical reactions by "MODEL" of EMF ("field/cloud") of a molecule of medical substance (including MS for anesthesia).

Explanation:

- the cascade of biochemical responses begins after conformation changes of the receptor;

- conformation changes of a receptor occurs at a stage of physical (electromagnetic) and chemical interactions (congruence mapping) of MS molecule and its receptor.

It is able to afford to provide effects of MS without introduction of its chemical "kernel" (the material substratum) to the patient's organism after creation:

- electromagnetic model of medical substance (EMMMS);

- technology of address placement of effective number of such units in localization zones of "narcotic receptors". 
2. A hypothesis (continuation) - address placement of EMMMS is possible by technologies of a Magnetic Resonance Tomography (MRT).

Explanation:

- MRT provides three-dimensional (3D) "picture" of the internal environment of a human body (organs, spaces, fabrics, the environments);

- MRT device creates this information ("picture") by using of information about layout (topography, 3D localization) $\mathrm{H}+$ ions;

- information about layout of ions of $\mathrm{H}+$ gathers from everyone, certain resolution capability of MRT device, point (the minimum section of a sample of object of research) of an organ, tissue;

- software by connecting such "points" creates 2D or 3D models of anatomic area of survey [20];

- it is possible in case of further development of MRT-technologies of imaging the device will receive such level of resolution capability (in these days it's 100 microns), which will allow to identify $\mathrm{H}+$ or other atoms in each molecules - structural units of RN [21-24];

- software will be able to create the electromagnetic circuit of $\mathrm{RN}$ - to visualize electromagnetic "field/cloud" of RN (3D features of its spatial structure) after integrating the spatial location EMF of each structural unit of RN;

- visualization of $\mathrm{RN}$ and its localization in $\mathrm{x}-\mathrm{y}-\mathrm{z}-\mathrm{coordinate}$ system of object of research will allow to create conformation specificity of each $\mathrm{RN}$ and its $3 \mathrm{D}$ address;

- information about conformation specificity of a receptor (its electromagnetic "mould") will allow to identify "the lock";

- the study by means of MRT of electromagnetic "field/cloud" of the existing MS (including for anesthesia) can create Basis of EMMMS ("keys").

3. The hypothesis (continuation) - implementation of address delivery is possible by means of a summation of technologies, which allow to see in a certain point of space the image of objects which there are absent (3D-holography, a laser light modeling) and the MRT technologies [25, 26].

Explanation:

- 3D MRT "picture" is created by trapping of changes of the summary magnetic moment/resonance of $\mathrm{H}+$ of object of study;

- author of this hypothesis (G.M.A.) is offered to make action on object that reverse to that, which is used in the case of visualization - to initiate the summary magnetic moment/resonance of $\mathrm{H}+$ in space points, according to "map" of 3D localization (the 3D address) and conformation specificity of receptors to MS ("locks");

- and it is necessary to induce the magnetic moment/resonance of $\mathrm{H}+$ so that it is "draw" 3D EMMMS to simulate "keys" for each "locks", to bring closer and connect this 3D EMMMS to electromagnetic "fields/cloud" of a narcotic receptor;

- after such "connection" of EMMMS and RN there will be a change of physical and chemical characteristics of RN to the subsequent start of all stages of the cellular response similar to what occurs in case of normal/natural MS;

- simulation of MS action on target cells will occur taking with the pharmacodynamic features of natural MS: concentration in the target areas, speed of communication rate and dissociation rate, duration of MS stay on RN and so on;

- quantity of EMMMS, which should be modeled, will correspond adequately to number of molecules from an average therapeutic dose of MS for achievement of desirable effect of anesthesia.

Algorithm of procedure (briefly, hypothesis):

1. The basis of $3 \mathrm{D}$ addresses of all narcotic receptors of this individual is created with the help of MRT of high resolution.

2. The basis of 3D circuits of electromagnetic "fields/clouds" of all narcotic receptors of this individual is created with the help of MRT of high resolution.

3. EMMMS is selected from earlier created Basis according to medical indications (set of control MRT commands, which will allow "to draw" and simulate a circuit of electromagnetic field of appropriate MS). 
4. The target dose - quantity of MS molecules, which is necessary have to model - quantity of EMMMS is calculated.

5. Specific/individual features of interaction of MS molecules that should be considered during the «delivery» of EMMMS are calculated.

6. The program of MRT operation (device with other name, for example "RFMRAInductor"), which according to pharmacodynamic features of natural MS will simulate estimated quantity of EMMMS according to unique 3D addresses RN.

\section{Conclusions}

Thus, in the presence of the Database of contours of the electromagnetic fields of MS molecules for anesthesia, a possibility of creation of the 3D individual base of addresses for all narcotic receptors $(\mathrm{RN})$, existence of formation algorithm of the MS electromagnetic models (EMMMS), existence of algorithm of EMMMS delivery to RN creation of the receptor-focused magnetic and resonant anesthesia is possible.

\section{References}

[1] Hovig, V., Roderic, G., Douglas, E. (2013). Anesthetic drug development: Novel drugs and new approaches. Surgical Neurology International, 4 (1), 2-10. doi: 10.4103/2152-7806.109179

[2] Sneyd, J. (2012). Novel etomidate derivatives. Current Pharmaceutical Design, 18 (38), 6253-6256. doi: 10.2174/138161212803832362

[3] Evers, A. S., Maze, M., Kharasch, E. D. (2011). Anesthetic Pharmacology: Basic Principles and Clinical Practice. Cambridge, United Kingdom: Cambridge University Press, 1, 210. doi: 10.1017/ CBO9780511781933

[4] Chabner, B. A., Knollman, B., Chabner, B., Brunton, L. (2011). Goodman and Gilman's The Pharmacological Basis of Therapeutics, Twelfth Edition. New York, United States: McGraw-Hill Education, 1808 .

[5] Chekman, I. S., Nebesna, T. Yu., Kazakova, O. O., Vysotskiy, A. O. (2013). Molekulyarna topologiya: noviy napryam u likoznavstvi. Science and Innovation, 9 (4), 73-78.

[6] Chekman, I. S. (2010). Kvantova farmakologiya - prostorova budova ta elektronna struktura molekul likarskih zasobiv (oglyad literaturi ta vlasnih doslidzhen). Journal of Academy of Medical Sciences of Ukraine, 16 (2), 213-224.

[7] Miller, R. ed. (2009). «Anesteziya» Ronalda Millera. Sankt-Peterburg: Chelovek, 2015, 3331.

[8] Miller, K. W., Orser, B. A., Roth, S. H. (2011). Mechanisms of anesthesia; past, present, and a glimpse into the future. Canadian Journal of Anesthesia, 58 (2), 131-138. doi: 10.1007/s12630$010-9433-y$

[9] Stoelting, R. K., Barash, P. G., Cullen, B. F., Cahalan, M. D. (2009). Clinical anesthesia. Philadelphia: Wolters Kluwer Health/Lippincott Williams and Wilkins, 1760.

[10] Torri, G. (2010) Inhalation anesthetics: a review. Minerva Anestesiology, 76 (3), 215-228.

[11] Urban, B. W. (2002) Concepts and correlations relevant to general anaesthesia. British Journal of Anaesthesia, 89 (1), 3-16. doi:10.1093/bja/aef164

[12] Långsjö, J. W., Alkire, M. T., Kaskinoro, K., Hayama H., Maksimow, A., Kaisti, K. K., Aalto, S., Aantaa, R., Jääskeläinen, S. K., Revonsuo, A., Scheinin, H. (2012). Returning from oblivion: imaging the neural core of consciousness. The Journal of Neuroscience, 32 (14), 4935-4943. doi: 10.1523/ jneurosci.4962-11.2012

[13] Special Issue of Anesthesia \& Analgesia to the 2015 International Mechanisms of Anesthesia Conference (MAC 2015) Available at: https://www.mac2015.uni-bonn.de/downloads-1/editorial-formac-2015-special-issue-of-a-a

[14] Darbinyan, T. M., Golovchinskiy, V. B. (1972). Mehanizmyi narkoza. Moscow: Medicine, 261.

[15] Abraini, J. H., Marassio, G., David, H. N., Vallone, B., Prangé, T., Colloc'h, N. (2014). Crystallographic Studies with Xenon and Nitrous Oxide Provide Evidence for Protein-dependent Processes in the Mechanisms of General Anesthesia. Anesthesiology, 121 (5), 1018-1027. doi: 10.1097/ aln.0000000000000435 
[16] Miller, K. W. (2002). The nature of sites of general anaesthetic action. British Journal of Anaesthesia, 89 (1), 17-31. doi:10.1093/bja/aef167

[17] Hansch, C., Fujita, T. (1964) $\rho-\sigma-\pi$ Analysis. A Method for the Correlation of Biological Activity and Chemical Structure. Journal of the American Chemical Society, 86 (8), 1616-1626. doi: $10.1021 / \mathrm{ja} 01062 \mathrm{a} 035$

[18] Chekman, I. S. (2011). Kvantovaya farmakologiya: sostoyanie, perspektivyi nauchnyih issledovaniy, vnedrenie rezultatov v prakticheskuyu farmatsiyu. Pharmatsevtichny magazine, 2, 43-48.

[19] Landau, L. D., Lifshits, E. M. (1989). Theoretical physics. Quantum electrodynamics, 728.

[20] Uebb, S. (1991). Fizika vizualizatsii izobrazheniy v meditsine. Moscow: Mir, 408.

[21] Bandettini, P. A., Bowtell, R., Jezzard, P. and Turner, R. (2012). Ultrahigh field systems and applications at $7 \mathrm{~T}$ and beyond: Progress, pitfalls, and potential. Magnetic Resonance in Medicine, 67, 317-321. doi: 10.1002/mrm.2315

[22] Formica, D., Silvestri, S. (2004) Biological effects of exposure to magnetic resonance imaging: an overview BioMedical Engineering OnLine, 3 (11), 12. doi: 10.1186/1475-925X-3-11

[23] Hartwig, V., Giovannetti, G., Vanello, N., Lombardi, M., Landini, L., Simi, S. (2009) Biological effects and safety in magnetic resonance imaging: a review. International Journal of Environmental Research and Public Health, 6 (6), 1778-1798. doi: 10.3390/ijerph6061778

[24] Vaynshteyn, B. K. (1987) Elektronnaya mikroskopiya atomnogo razresheniya. Achievements of physical sciences, 152 (1), 75-122.

[25] Gabor, D. (1973) Golografiya. Achievements of physical sciences, 109 (1), 5-30.

[26] Lider, V. V. (2015) Rentgenovskaya golografiya. Achievements of physical sciences, 125 (4), 393-413. doi: 10.3367/UFNr.0185.201504d.0393 